\title{
Textural, Rheological and Sensory Properties of Spreadable Processed Goat Cheese
}

\author{
Laura Burgos ${ }^{\mathrm{a}^{*}, \mathrm{c}}$, Nora Pece ${ }^{\mathrm{b}}$, and Silvina Maldonado ${ }^{\mathrm{a}}$ \\ ${ }^{\text {a }}$ Laboratorio Ingeniería para el Desarrollo de la Agroindustria Regional (IDeAR), Facultad de Ingeniería, \\ Universidad Nacional de Jujuy, Ítalo Palanca 10, 4600, Jujuy, Argentina \\ b Instituto de Ciencia y Tecnología de Alimentos, Facultad de Agronomía y Agroindustrias, Universidad \\ Nacional de Santiago del Estero, Belgrano (S) 1912, 4200, Santiago del Estero, Argentina \\ ${ }^{c}$ Consejo Nacional de Investigaciones Científicas y Técnicas (CONICET), Argentina \\ ${ }^{*}$ Corresponding author \\ laura.burgos@conicet.gov.ar
}

Received: 22 November 2018; Published online: 18 January 2020

\begin{abstract}
The aim of this work was to study the influence of the ripening degree of natural goat cheese on texture, rheological and sensory properties of processed cheese products. Processed cheeses were formulated using goat cheeses with 10, 20 and 40 days of ripening. We obtained four different formulations by varying the proportions of these cheeses in each formulation. The variation in major $\alpha, \beta$ and para- $\kappa$ casein fractions, rheological properties and the texture of samples were determined, and a sensorial evaluation was carried out. Cheeses from Formulation 2 (50\% cheese ripened for 10 days, $25 \%$ cheese ripened for 20 days and $25 \%$ cheese ripened for 40 days) had greater values of $\alpha$ and $\beta$-caseins, which is related to a greater content of intact casein resulting from a cheese with short ripening time. Hardness, adhesiveness and complex modulus $\left(\mathrm{G}^{*}\right)$ decreased as the degree of ripening of the natural cheese (raw material) increased. Formulation 2 presented a $G^{*}$ value similar to that of the commercial processed cow cheese and the greatest firmness. Formulation 2 presented the characteristics we aimed to obtain, described as spreadable, slightly acid and salty cheese.
\end{abstract}

Keywords: Casein; Texture; Sensory characterization; Goat cheese; Complex modulus

\section{Introduction}

Processed cheese is elaborated by blending natural cheese of different ages and degrees of maturity in the presence of emulsifying salts and other dairy and non-dairy ingredients, followed by heating and continuous mixing to form a homogeneous product with an extended shelf life (Guinee, Carić, \& Kalab, 2004). Different parameters are modified in the production of processed cheese, affecting the rheological behavior of the molten mass during processing and the texture of the final product. These parameters are ripening of natural cheese (i.e. the degree of proteolysis), $\mathrm{pH}$ of cheese melt, type and concentration of emulsifying salts, processing and storage conditions (processing temperature, speed of agitation, duration of heating, rate of cooling and temperature of storage), dry matter content, fat content, presence and concentration of ions (especially calcium, sodium and potassium) and use of hydrocolloids (Cernikova et al., 2008; Piska \& Stetina, 2004).

The characteristics of natural cheese utilized to manufacture processed cheese have a major influence on processed cheese characteristics; therefore, appropriate selection of natural cheese is critical in order to achieve a pro- 
cessed cheese with the desired chemical and functional characteristics. The natural cheese used in a processed cheese formulation is generally selected on the basis of type, flavor, maturity, consistency, texture and $\mathrm{pH}$ (Piska \& Stetina, 2004). Kapoor, Metzger, Biswas, and Muthukummarappan (2007) highlighted the importance of total intact casein in the quality of processed cheese. Once again, the major ingredient that contributes to the intact casein in a processed cheese formula is the type and age of the natural cheese used in the formula.

Regarding processed cheese, several studies have been carried out on sensory characterization in relation to processing factors and chemical composition. Their effects on structure, texture and rheological properties have been studied in order to improve knowledge and obtain acceptable products (Cernikova et al., 2008; Piska \& Stetina, 2004). In these studies, descriptive sensory analysis was used for characterization of processed cheeses. New methods for sensory product characterization continue to be developed. Novel techniques are based on the evaluation of individual attributes, among which are intensity scales, check-all-that-apply questions or CATA, flash profiling and paired comparisons (Varela \& Ares, 2012). It has been shown that results from CATA questions used with consumers are very similar to those obtained from trained panels (Bruzzone, Ares, \& Giménez, 2012).

The chemical composition of goat milk and the content of each component make it possible to obtain cheeses with sensorial characteristics distinct from those obtained from cow milk. Semihard goat cheese is whiter than cheese made from cow milk, which presents an intense yellow color (Galván, 2007). Goat cheeses are usually soft and wet, and have high initial fermentative flavor, with predominant goat milk and lactic aroma. They present a plastic structure, are slightly firm, have adherence, a microstructure formed by small particles, high solubility and moisture sensation in mouth. They have an acid and slightly salty taste, characteristic aftertaste and medium to long term persistence.

Many studies about processed cheeses manufactured with cow milk describe rheological characteristics, textural and sensory parameters such as spreadability, firmness, softness, creaminess, taste and flavour (Cernikova et al., 2008; da Silva, de Souza Ferreira, Bruschi, Britten, \& Matumoto-Pintro, 2016; Dimitreli \& Thomareis, 2008; Hanaei, Cuvelier, \& Sieffermann, 2015; Salek, Cernikova, Maderova, Lapcik, \& Bunka, 2016). These kinds of cheese present a spreadable texture, brilliant white to yellow color, and flavor that depends on the ripened cheeses and the ingredients used for manufacture. They show a smooth and closed surface when cutting, and some small bubbles could appear as a result of the filling stage.

The dependence of texture parameters (measured within the deformation area), and rheological and sensory properties of the processed goat cheese on the maturity of cheese (raw material) have not been described in the literature. In addition, processed goat cheese is not currently on the market in Northwestern Argentina, where the study was conducted. The aim of this work was to determine how the ripening degree of the natural goat cheese (raw material) influences the textural, rheological and sensory properties of processed cheese products.

\section{Materials and Methods}

\subsection{Processed cheese manufacturing}

Different samples of processed cheeses were obtained by using goat cheeses ripened for 10 , 20 and 40 days and made from pasteurized milk in the traditional way; cream; water; and 2.8 (g/100g) emulsifying salts JOHA S10 2.5 (g/100g) and JOHA HBS $0.3(\mathrm{~g} / 100 \mathrm{~g})$; sodium phosphate and polyphosphate salts. The composition of the ingredients and the processed cheese are shown in Table 1 . The ingredients were smelted in an electric heater in combination with an omnimixer at $85{ }^{\circ} \mathrm{C}$ for $1 \mathrm{~min}$ (total melting time was $9 \mathrm{~min}$ at $1358 \mathrm{~g}$ ). The hot melt was poured into cylindrical polyethylene containers (35 $\mathrm{mm}$ in diameter and $50 \mathrm{~mm}$ in height). Finally, the samples were cooled to $7^{\circ} \mathrm{C}$.

During the manufacturing process, we varied the proportion of cheese (raw material), with different ripening times, to obtain the different formulations shown in Table 2. 
Table 1: Composition of processed goat cheese and its ingredients

\begin{tabular}{ccc}
\hline & $\begin{array}{c}\text { Dry Matter }(\mathrm{DM}) \\
\mathrm{g} / 100 \mathrm{~g}\end{array}$ & $\begin{array}{c}\text { Fat } \\
\mathrm{g} / 100 \mathrm{~g} \text { DM }\end{array}$ \\
\hline Processed goat cheese & 37 & 53 \\
Goat cheese ripened & & \\
10 days & 58 & 46.5 \\
20 days & 62 & 48 \\
40 days & 70 & 50 \\
Cream & 46.8 & 42 \\
\hline
\end{tabular}

Table 2: Proportions of ripened cheeses in each formulation of processed cheese

\begin{tabular}{cccc}
\hline \multirow{2}{*}{ Formulation } & \multicolumn{3}{c}{ goats cheese proportions } \\
\cline { 2 - 4 } & 10 days & 20 days & 30 days \\
\hline 1 & 1 & 1 & 1 \\
2 & 2 & 1 & 1 \\
3 & 1 & 2 & 1 \\
4 & 1 & 1 & 2 \\
\hline
\end{tabular}

The resulting processed cheeses were analyzed using three replicates of each assay and every test was performed in triplicate. No processed goat cheese was available on the market, and therefore our results were compared to a commercial reference made solely from natural cow cheeses. The composition of the commercial reference was similar to that of our samples (35 dry matter $\mathrm{g} / 100 \mathrm{~g}$, 52 fat $\mathrm{g} / 100 \mathrm{~g}$ in dry matter). This commercial processed cheese was purchased in the local market and selected from three different lots.

\subsection{Casein fractions of processed cheeses (PC)}

The variation in major fractions of $\alpha, \beta$ and para- $\kappa$ casein was studied using HPLC ion exchange, following the methodology described by Veloso, Teixeira, and Ferreira (2002). The HPLC equipment consisted of a Spectra SYSTEM Thermo Electron chromatograph, equipped with a P2000 pump and a Rheodyne Injector with a $20 \mu$ l loop. A Spectra SYSTEM UV 6000LP PDA, variable-wavelength ultraviolet detector was used. ChromQuest 4.1 SP2 software con- trolled the solvent gradient, data acquisition and data processing of the equipment. The column was a reversed-phase Phenomenex C18 $(5 \mu \mathrm{m}$, $300 \AA, 250 \times 4.6$ I.D.). Gradient elution was carried out with a mixture of two solvents. Solvent A consisted of $0.1 \%$ trifluoroacetic acid (TFA) in water and solvent B was acetonitrile-water-TFA (95:5:0.1, v/v). Proteins were eluted with a series of linear gradients increasing the proportion of solvent A, from $29 \%$ to $100 \%$ over 40 min. The flow rate was $1 \mathrm{ml} / \mathrm{min}$, the column temperature was $46 \pm 0.1^{\circ} \mathrm{C}$ and the eluate was monitored at $280 \mathrm{~nm}$.

\subsection{Texture analysis}

The texture was determined using an InstronBluehill ${ }^{\circledR}$ texturometer. The tests were carried out at $6 \pm 2{ }^{\circ} \mathrm{C}$ (the sample measurement was performed immediately after removing them from a refrigerator where they were stored) after two days of storage according to the methodology described by Piska and Stetina (2004) and Weiserova et al. (2011). The parameters used in the tests were 
double penetration of $30 \mathrm{~mm}$ into the samples, speed penetration of $1 \mathrm{~mm} / \mathrm{s}$, bristle of $10 \mathrm{~N}$, penetrometer diameter of $12 \mathrm{~mm}$ and cylinder diameter of $36 \mathrm{~mm}$ at $10{ }^{\circ} \mathrm{C}$ (Lemes et al., 2016). According to the force deformation curve describing the dependence of the force needed $(\mathrm{N})$ on time $(\mathrm{s})$, the following textural parameters were determined: hardness, cohesiveness and adhesiveness (Weiserova et al., 2011). Each variant was measured six times.

\section{Rheological measurements}

The processed cheese samples were characterized in terms of their rheological properties. Rheological measurements were made using an AR-G2 rheometer (TA Instruments; New Castle, DE, USA) with parallel plate geometry $(40 \mathrm{~mm}$ diameter, $2 \mathrm{~mm}$ gap). Temperature $\left(2{ }^{\circ} \mathrm{C}\right)$ was controlled with a water bath (Julabo ACW100, Julabo Labortechnik; Seelbach, Germany) associated with the rheometer. The linear viscoelastic region was determined by an amplitude sweep test, while the frequency sweep mode was used to evaluate the viscoelastic properties of model samples. The storage $\left(G^{\prime}\right)$ and loss $\left(G^{\prime \prime}\right)$ moduli were measured in the $0.1-100.0 \mathrm{~Hz}$ frequency range. The loss tangent $(\tan \delta$ ) and complex modulus $\left(G^{*}\right)$ for the reference frequency $1 \mathrm{~Hz}$ were calculated according to Eq. (1) and (2) (Gunasekaran \& Ak, 2000):

$$
\begin{gathered}
\tan \delta=\frac{G^{\prime \prime}}{G^{\prime}} \\
G^{*}=\sqrt{G^{\prime 2}+G^{\prime \prime 2}}
\end{gathered}
$$

The value of $1 \mathrm{~Hz}$ for reference frequency was recommended in the literature (Bennett et al., 2006; Piska \& Stetina, 2004).

\subsection{Sensory evaluation of processed cheeses}

The participants in this study $(\mathrm{n}=100,23-68$ years old, $62 \%$ female) were regular consumers of goat cheese but non-regular consumers of processed cheeses. They were recruited in cafeterias and public areas of the University of Jujuy, Jujuy Province, Argentina.

The consumers received a single CATA question featuring 24 attributes, which had been previously selected from the available literature (Hanaei et al., 2015) and from the results of an informal tasting session conducted by researchers of the university. The instruction given to participants was 'Please, check all that applies to the processed cheese you taste'. The 24 selected attributes were randomized between products and across consumers. The following terms were used: thick, smooth goat milk flavor, strange taste, soft flavor, creamy, very salty, homogeneous, firm, slightly sour, not creamy enough, strong aroma of goat milk, soft texture, aftertaste, pleasant appearance, liquid, very sour, not salty enough, lumpy, fluid, aroma of goat milk, intense goat milk taste, salty, spreadable and heterogeneous. Consumers were asked to try the cheeses individually and spread them on a toast, in the way spreadable cheeses are usually consumed. They evaluated the cheeses' general acceptance using a nine-point hedonic scale, with 1 being the worst and 9 the best quality. Consumers were finally asked if they would buy the product.

The attributes were randomized within each modality between products and across consumers. The frequency of use of each sensory attribute was determined by counting the number of consumers that used that term to describe each sample. Cochran's Q test was carried out to identify significant differences among samples for each of the descriptors included on the CATA question. The frequency (contingency) tables from each study were analyzed using Correspondence Analysis (CA). Bi-dimensional maps representing samples and descriptors were obtained. The maps that corresponded to all the consumers who participated in the test were used as a reference for evaluating the stability of product spaces.

The authors declare that, in Argentina, approval of an Ethics Committee is not needed for Sensorial Analysis. Nevertheless, these analyses were carried out following international tenets and informed consents were obtained.

\subsection{Statistical analysis}

All the formulations were prepared in triplicate. Minitab 16.0 statistical software (Minitab Inc., 
State College, PA, USA) was used for analyzing the experimental data. One-way analysis of variance was used to determine significant differences between means, with the level of significance (p) set at 0.05 . Tukey's HSD test at $5 \%$ significance level was used as the multiple comparison tests on all main effect means. All statistical analyses of sensory evaluation were performed using XLStat 2009 (Addinsoft, Paris, France) and R language (R Development Core Team, 2007) using FactoMineR (Le, Josse, \& Husson, 2008).

\section{$3 \quad$ Results and Discussions}

\subsection{Casein fractions of PC}

The casein fractions obtained in each cheese spread formulation are presented in Figure 1. The contents of $\alpha$-casein in the formulations studied were ordered from highest to lowest: Formulation 2, Formulation 1, Formulation 3 and Formulation 4. This decreasing level in the contents of $\alpha$-casein is due to the slow casein hydrolysis throughout 30 days of ripening (Burgos, 2016). By contrast, greater intact casein was present in cheeses with 10 days of ripening, resulting in the major casein content of Formulation 2.

Guinee and O'Callaghan (2013) studied the effects of protein and fat content on the properties of a processed cheese by substituting the protein with fat while maintaining constant moisture and emulsifying salt levels. The firmness of the processed cheese increased markedly with increased protein levels. Greater protein content in the formulation allows higher caseincasein interaction and stabilizes the cheese matrix (Hosseini-Parvar, Matia-Merino, \& Golding, 2015). Dimitreli and Thomareis (2008) reported that proteins reinforce the strength of the threedimensional matrix, leading to processed cheeses with more solid-like behavior.

The $\beta$-casein and para- $\kappa$-casein contents, in Formulations 1 and 4 , which were lower than those in the other two formulations, showed significant differences between them. Both casein fractions got hydrolyzed as from day 30 . Formulations 1 and 4 had a higher proportion of cheeses (raw material) ripened for 40 days, and therefore their hydrolyzation of casein fractions was higher. The intact casein content of the cheese is inversely related to the age of the cheese. As a natural cheese is ripened, its intact casein content decreases (Kapoor \& Metzger, 2008). This occurs because the enzymes and the residual starter or nonstarter lactic acid bacteria present in the cheese hydrolyze the proteins of natural cheese into peptides, thereby reducing the amount of casein that is still present in the intact (unhydrolyzed) form (Purna, Pollard, \& Metzger, 2006).

The proportion of the different casein fractions in the cheeses produced different characteristics in the processed cheese matrix obtained with each formulation. Salek et al. (2016) indicated that the degree of casein proteolysis in the cheese applied during PC manufacture is a parameter that significantly influences its textural and viscoelastic properties (Brickley, Auty, Piraino, \& McSweeney, 2007; Bunka et al., 2014; Piska \& Stetina, 2004).

\subsection{Texture Analysis}

Table 3 show the results obtained for textural parameters: hardness, cohesiveness, springiness and adhesiveness.

The hardness of a matrix is used as an index of product strength while cohesiveness indicates the strength of internal bonding of the processed cheese (da Silva et al., 2016). Adhesiveness is the tendency of the processed cheese to resist separation from a material it contacts. High adhesiveness of processed cheese to the packaging material is one of the parameters limiting their consumption since consumers dislike products that are difficult to separate from the package (Hosseini-Parvar et al., 2015; Solowiej, Cheung, \& Li-Chan, 2014); another parameter is the stickiness that occurs in the mouth as a sensory consequence.

We observed that cohesiveness was statistically similar in all studied samples. Hardness and adhesiveness increased in the following order: Formulations 4, 3, 1 and 2, followed by the commercial processed cow cheese (CPCC). Springiness of formulations 1, 2, 3 and CPCC was similar. Formulation 4 was elaborated with the largest pro- 
portion of long-ripened cheese (40 days of ripening) and presented lower values of textural parameters than those of processed cheeses with the largest proportion of short-ripened cheeses, except for cohesiveness. This behavior was due to the higher content of hydrolyzed caseins in these cheeses.

We can relate the increase in the proportion of ripened cheese to the decrease in hardness and adhesiveness in the processed cheeses. Similar conclusions were drawn by Piska and Stetina (2004) when they studied cow processed cheese formulated with soft, semi-hard and hard cheeses with different ripening times, and by Hladka et al. (2014) who obtained processed cheeses using Edam cheese with different ripening times.

Brickley et al. (2007) studied the relationship between cheddar cheese ripening, with the emphasis being on proteolytic breakdown, and the resultant textural changes in PC manufactured from cheddar cheese. Using multivariate data analysis, they concluded that the concentration of intact $\alpha \mathrm{s} 1-\mathrm{CN}$ in cheddar cheese was strongly correlated with the decrease in hardness, fracturability, springiness, adhesiveness and G' in the corresponding PC samples. Flowability increased in the PC samples and it was correlated with the production of free amino acids in cheddar cheese as well as development of the protein content of the $\mathrm{pH} 4.6$ soluble fraction.

Besides, the influence of different maturity degrees of natural cheese was associated with different ternary mixtures of emulsifying salts affecting PC texture. The effect of composition of different ternary mixtures of the individual sodium salts of phosphates (especially disodium hydrogenphosphate, tetrasodium diphosphate, and sodium salt of polyphosphate) has been described by Bunka et al. (2014), Weiserova et al. (2011) and Salek et al. (2016). The higher the amount of emulsifying salts, the higher the hardness and cohesiveness of the processed cheeses was. Changing concentration of the emulsifying salts and $\mathrm{pH}$ adjustment to the optimal range ( $\mathrm{pH}$ in the range of 5.695.84 ) only affected the absolute values of textural parameters of the processed cheeses (Bunka et al., 2014).

Moreover, values of the studied texture parameters for each formulation were lower than those of the commercial reference, probably be- cause of the use of hydrocolloids by the industry to achieve a stable texture. Macku, Bunka, Voldanova, and Pavlinek (2009) stated that hydrocolloid incorporation can cause changes in product structure and texture (Bennett et al. 2006). These hydrocolloids (so-called stabilizing, gelling or thickening agents) can improve texture and consistency of food by water binding, gel creation or viscosity enhancing. Commercially important hydrocolloids which can be used in dairy industry are carrageenan, locust bean gum, xanthan, modified starches and pectin (Bennett et al., 2006).

The textural characteristics of Formulation 2 cheeses were similar to those of the commercial processed cow cheese used as a reference. This formulation produced a product with the desired texture, even without hydrocolloid or starch incorporation. The greater $\alpha$ and $\beta$ casein contents could explain this effect, which allowed the formation of a firmer gel than that of the other formulations.

\subsection{Rheological Properties}

Table 4 shows complex modulus $\mathrm{G}^{*}(\mathrm{~Pa})$ and the loss tangent $(\tan \delta)$ of all formulations and commercial processed cow cheese, at a frequency of $1 \mathrm{~Hz}$.

Formulation 2 samples presented significant differences in $\mathrm{G}^{*}$ and showed similar results to those of the commercial processed cow cheese, with a 95\% significance level. This modulus describes the total resistance of the cheese matrix, considering the deformation behavior of the samples as elastic solids (Dimitreli \& Thomareis, 2008). As shown in Table 4, Formulation 2 samples presented the greatest resistance. The behavior of the four studied formulations could be explained by their high $\alpha$ - and $\beta$-casein content, which allows the formation of a firm casein gel lubricated with fat, producing viscoelastic properties similar to those of the reference.

The higher protein content in the formulation allows more casein-casein interaction and stabilizes the cheese matrix (Hosseini-Parvar et al., 2015). Dimitreli and Thomareis (2008) reported that proteins reinforce the strength of the threedimensional matrix, leading to processed cheeses 
Table 3: Textural parameters in goat formulations and commercial processed cow cheese (CPCC)

\begin{tabular}{cccccc}
\hline & \multicolumn{4}{c}{ Formulation } & \multicolumn{2}{c}{ CPCC } \\
\cline { 2 - 5 } & 1 & 2 & 3 & 4 & 5 \\
\hline Hardness (N) & $0.47 \pm 0.07^{(b)}$ & $0.9 \pm 0.1^{(c)}$ & $0.4 \pm 0.1^{(b)}$ & $0.22 \pm 0.02^{(a)}$ & $2.2 \pm 0.2^{(d)}$ \\
Adhesiveness (N.s) & $6.2 \pm 0.1^{(b)}$ & $14.2 \pm 0.1^{(c)}$ & $5.3 \pm 0.9^{(a b)}$ & $2.5 \pm 0.8^{(a)}$ & $32.9 \pm 0.9^{(d)}$ \\
Cohesiveness & $0.83 \pm 0.09^{(a)}$ & $0.94 \pm 0.08^{(a)}$ & $0.82 \pm 0.08^{(a)}$ & $0.87 \pm 0.08^{(a)}$ & $0.83 \pm 0.03^{(a)}$ \\
\hline
\end{tabular}

${ }^{a b c}$ Means $(\mathrm{n}=6)$ within the same line and parameter followed by different superscript are significantly different $(\mathrm{P}<0.05)$.

with more solid-like behavior. The higher values of the gel strength may be explained by more intensive interactions occurring in the cheese samples, such as hydrogen bonds, hydrophobic interactions between caseins and fat or calciumintervened electrostatic bonds among caseins, leading to the formation of a "denser" (more intensive) network structure (Salek et al., 2016). Guinee (2016) stated that increasing the protein content of cheese results in significant increases in storage modulus, firmness (force required to attain a given deformation) and fracture stress of the unheated cheese. This is confirmed by the positive correlations between the content of intact casein and fracture stress and firmness of Cheddar processed cheeses.

Cunha, Grimaldi, Alcantara, and Viotto (2013) indicated that the high values of G' were due to the combined effects of a low degree of casein dissociation and a low percentage of soluble calcium/total calcium, which resulted in a more elastic protein network. These authors argued that increasing $\mathrm{pH}$ increases the negative charge of the protein molecules, causing their repulsion and expansion. In processed cheese, ionic repulsion in the $\mathrm{pH}$ range 5.7 to 6.0 , instead of totally dispersing proteins, enhances different types of interactions, such as noncovalent bonds (hydrogen bonds, hydrophobic and electrostatic interactions), thus increasing elasticity. These changes resulted in an increase in casein hydration and in the formation of a more open reactive structure with higher water-binding capability and better emulsifying properties.

The $\tan \delta$ gave a clear indication of whether elastic or viscous properties of processed cheese predominated (Table 4). The larger the $\tan \delta$ value, the more the cheese flowed. The loss tangent values showed a predominantly viscoelastic behavior $\left(\tan \delta>1\right.$ or $\mathrm{G}^{\prime \prime}>\mathrm{G}^{\prime}$ ) (Dimitreli \& Thomareis, 2008) for samples formulated over the whole range of frequency tested. In our study, all tested formulations exhibited characteristics typical of a weak viscoelastic gel and presented values different from those of the commercial reference, which had a higher viscous component (0.6). The PC of formulation 4 had lower $\tan \delta$ values (0.4) and were weaker gels due to the higher content of ripened cheese.

According to Dimitreli and Thomareis (2008), when the protein content is increased, the elastic and viscous moduli and complex modulus are increased and the loss tangent is increased, indicating a more liquid-like behavior of the samples. This agrees with the results of Joshi, Jhala, Muthukumarappan, Acharya, and Mistry (2004), who reported that proteins are responsible for increased values of the elastic and viscous module in processed cheese samples. Increasing concentration of caseins in the cheese matrix increases the intra- and inter-strand linkages. The matrix displays greater elasticity and it is more difficult to deform. The unfolded protein molecules approach each other by attractive forces, and water and fat globules are trapped into the matrix. Thus, after cooling, the role of proteins in the texture of the final product dominates over that of water and fat, resulting in products with increased viscoelastic properties and a more solidlike behavior.

Hosseini-Parvar et al. (2015) showed that $\tan \delta$ (G" /G') may be a useful indicator of processed cheese meltability. The $\tan \delta$ values increased with the increase in the protein concentration 
while heating the samples up to $85{ }^{\circ} \mathrm{C}$. Proteinprotein interactions, at this temperature, increased the viscous behavior.

\subsection{Sensory evaluation of PC}

Q - Cochran Test results are shown in Table

5. Significant differences were found in the frequency at which 11 out of the 24 terms of the CATA question were used to describe the texture of the samples. This result suggests that the consumers were able to perceive differences in the sensorial characteristics of the evaluated processed cheese.

When we analyzed the frequency of responses, we found that the most widely used terms were thick, smooth goat milk flavor, homogenous, salty, smooth goat milk taste, creamy, pleasant appearance, spreadable, slightly sour and soft texture. Only four of these descriptors were significant, namely thick, salty, spreadable and slightly sour. These attributes describe the desired product.

Analyzing results presented in Table 5 and considering the significant parameters and the maximum values for each sample, we can state that the attributes which best describe the processed cheeses were as follows:

F1 intense goat milk taste

F2 spreadable, slightly sour, intense goat milk taste

F3 lumpy

F4 not creamy enough, very sour, fluid, salty.

CPCC 5 thick, firm, not too salty.

Figure 2 presents the first two dimensions of Correspondence Analysis of frequency data, where the relationship between the significant terms obtained with the Q - Cochran test for all the studied formulations can be seen.

As shown in the sensorial map, the first and second dimensions of the CA accounted for $90.78 \%$ of the variance of the experimental data, representing $68.8 \%$ of $\mathrm{F} 1$ and $21.98 \%$ of $\mathrm{F} 2$. We can distinguish three groups with different characteristics, as follows:

GI: Formulations 1 and 4 , characterized by intense goat milk taste, and as not creamy enough, very sour, fluid.

GII: Formulations 2 and 3, characterized as spreadable, slightly sour, salty, lumpy.

GIII: Commercial processed cow cheese (5), characterized as thick, firm, not salty enough. According to these results, the commercial processed cow cheese is different from the others, mainly because of its texture. We found that consumers were able to perceive the firmness of this product, which resulted from the presence of carrageenan.

Formulations $1 \quad(5.7 \pm 0.3), \quad 2 \quad(6.2 \pm 0.2), \quad 3$ $(6.0 \pm 0.6)$ and the commercial reference $(6.3 \pm 0.4)$ presented similar acceptance levels, while formulation $4(5.1 \pm 0.1)$ had the least acceptance due to its low creamy content, fluid texture and acid taste, attributes that were not desired.

Thirty percent of the consumers perceived differences when the cheeses were tasted with toast. This perception was similar between formulations, probably due to the masking of the cheese flavor by the toast.

Seventy percent of the consumers stated their intention of buying cheeses with Formulations 2, 3 and the commercial reference, confirming that formulations 2 and 3 presented acceptable sensorial characteristics and that they were similar to the commercial reference. Fifty-eight percent of the consumers expressed their intention of buying Formulation 1, and $38 \%$ of the consumers said they would buy Formulation 4. Sensorial evaluation of cheeses with each formulation and of the commercial reference showed differences between samples, both in the terms that describe them and in their acceptability, which is related to the consumer's intention to buy the product. Formulation 2 showed spreadable texture, brilliant white color and the characteristic flavor of goat cheese. These attributes were desired for the finished product, which was verified with the Q - Cochran test and the results of the Correspondence Analysis. 
Table 4: Complex modulus $\left(\mathrm{G}^{*}\right)$ and $\tan \delta$ of processed cheese for all formulations (1-4) and commercial processed cow cheese (5)

\begin{tabular}{ccc}
\hline Formulation & $\mathrm{G}^{*}(\mathrm{~Pa})$ & $\mathrm{Tan} \delta$ \\
\hline 1 & $1498 \pm 380^{(b)}$ & $0.50 \pm 0.03^{(b)}$ \\
2 & $2822 \pm 208^{(c)}$ & $0.51 \pm 0.04^{(b)}$ \\
3 & $1390 \pm 316^{(b)}$ & $0.51 \pm 0.02^{(b)}$ \\
4 & $872 \pm 231^{(a)}$ & $0.46 \pm 0.05^{(a)}$ \\
5 & $2701 \pm 306^{(c)}$ & $0.61 \pm 0.03^{(c)}$ \\
\hline$a b c$
\end{tabular}

${ }^{a b c}$ Means $(\mathrm{n}=6)$ within the same column and parameter followed by different superscript are significantly different $(\mathrm{P}<0.05)$.

Table 5: Results of the CATA question. Frequency at which each term was used to describe each processed cheese for all formulations (1-4) and commercial processed cow cheese CPCC (5)

\begin{tabular}{|c|c|c|c|c|c|}
\hline \multirow[t]{2}{*}{ Term } & \multicolumn{3}{|c|}{ Formulations } & \multicolumn{2}{|c|}{$\mathrm{CPCC}$} \\
\hline & 1 & 2 & 3 & 4 & 5 \\
\hline Thick * & 26 & 38 & 32 & 18 & 64 \\
\hline Soft flavor $n s$ & 36 & 38 & 44 & 48 & 46 \\
\hline Homogeneous ${ }^{n s}$ & 32 & 38 & 28 & 32 & 44 \\
\hline Not creamy enough $*$ & 18 & 8 & 8 & 28 & 18 \\
\hline Aftertaste $^{n s}$ & 18 & 12 & 14 & 18 & 8 \\
\hline Very sour $*$ & 24 & 14 & 8 & 34 & 4 \\
\hline Fluid * & 14 & 4 & 6 & 28 & 0 \\
\hline Salty * & 36 & 42 & 44 & 48 & 12 \\
\hline Smooth goat milk flavor $n s$ & 34 & 44 & 48 & 32 & 36 \\
\hline Creamy $n s$ & 44 & 58 & 48 & 30 & 50 \\
\hline Firm $*$ & 8 & 26 & 28 & 2 & 56 \\
\hline Strong aroma of goat milk ${ }^{n s}$ & 4 & 14 & 8 & 14 & 12 \\
\hline Pleasant appearance ${ }^{n s}$ & 44 & 54 & 52 & 36 & 52 \\
\hline Not salty enough $*$ & 14 & 8 & 18 & 14 & 32 \\
\hline Aroma of goat milk $n s$ & 22 & 16 & 20 & 22 & 12 \\
\hline Spreadable ${ }^{*}$ & 40 & 52 & 30 & 22 & 40 \\
\hline Strange taste ${ }^{n s}$ & 4 & 12 & 8 & 18 & 12 \\
\hline Very salty $n s$ & 20 & 12 & 10 & 24 & 6 \\
\hline Slightly sour * & 36 & 44 & 38 & 40 & 16 \\
\hline Soft texture ${ }^{n s}$ & 46 & 34 & 28 & 32 & 34 \\
\hline Liquid ${ }^{n s}$ & 2 & 2 & 0 & 20 & 0 \\
\hline Lumpy * & 10 & 16 & 28 & 8 & 0 \\
\hline Intense goat milk taste $*$ & 20 & 20 & 6 & 16 & 6 \\
\hline Heterogeneous ${ }^{n s}$ & 6 & 6 & 8 & 2 & 0 \\
\hline
\end{tabular}

* indicates significant differences at $\mathrm{P}<0.05$,

$n s$ whereas ns indicates no significant differences

$(\mathrm{P}>0.05)$ according to $\mathrm{Q}$ Cochran's test. 


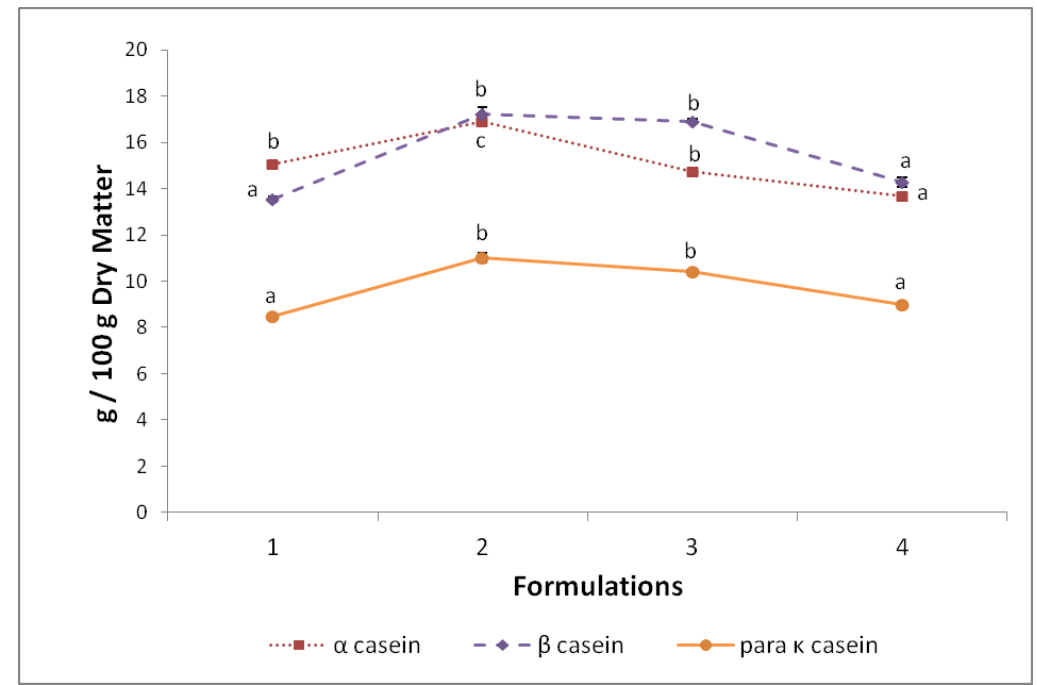

Figure 1: $\alpha$-casein $\boldsymbol{\square}, \beta$-casein and para- $\kappa$-casein• in formulations of processed cheese. The points with the different letters are significantly different $(\mathrm{P}<0.05)$.

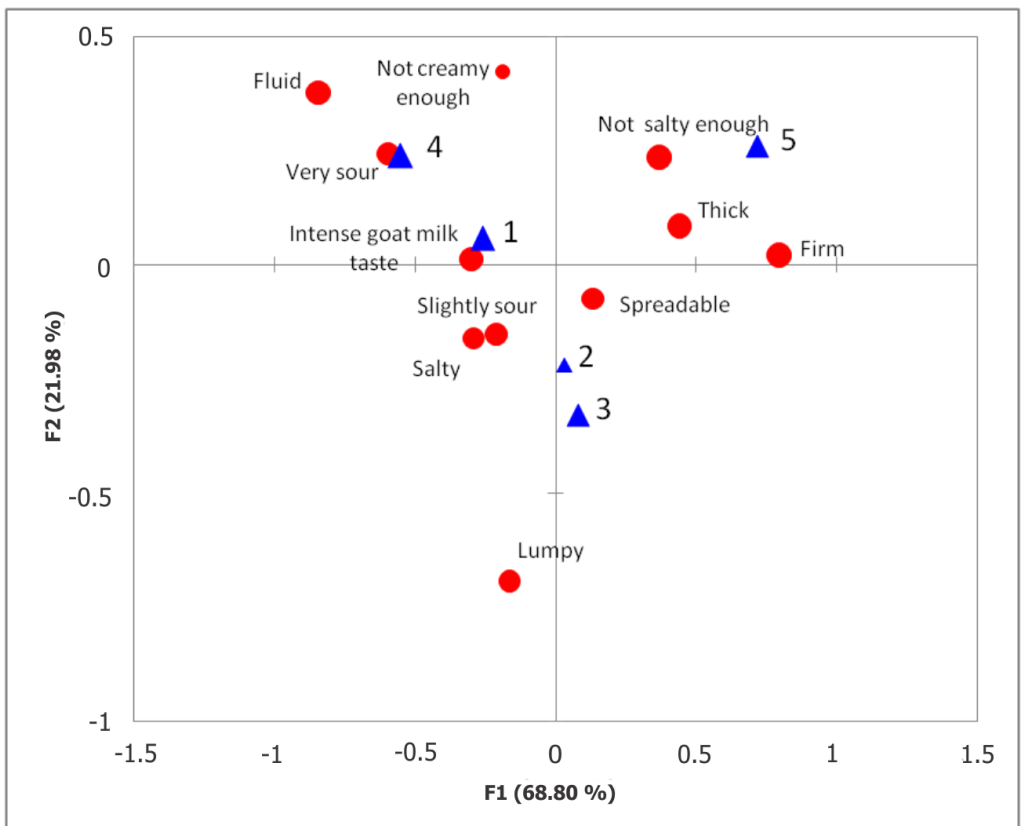

Figure 2: Sensorial map of significant terms. Representation of the formulations and reference processed cheese $\boldsymbol{\Delta}$ and the terms $\bullet$ of Check-All-That-Apply (CATA) question in the first two dimensions of the multiple factor analysis of CATA counts. 
The quality of a product and its acceptability are directly related to the quality of the raw material. Raynal-Ljutovac, Lagriffoul, Paccard, Guillet, and Chilliard (2008) argued that the characteristics of the milk itself have an impact on goat cheese characteristics but the cheese making steps may change the nutritional and sensorial characteristics of the final product. The processed goat cheeses obtained represent a high quality product that adds value to the goat milk sector.

The level of acceptance obtained represents a very important result considering that the sensorial evaluation was performed by nonhabitual consumers of processed cheeses. This acceptance is an indicator that local producers could introduce such a product into the local market.

\section{Conclusion}

Hardness and adhesiveness in the PC samples decreased as the proportion of ripened cheeses used in the formulation increased, which is associated with intact casein content. All spreadable processed goat cheese formulations appeared as a gel, as shown by the values of the storage and loss moduli $\left(\mathrm{G}^{\prime}>\mathrm{G}^{\prime \prime}\right)$. Formulation 2, made from $50 \%$ cheese ripened for 10 days, $25 \%$ cheese ripened for 20 days, and $25 \%$ cheese ripened for 40 days, presented a complex modus $\left(\mathrm{G}^{*}\right)$ similar to that of the reference. The resulting high firmness of the gel in Formulation 2 was due to the higher content of $\alpha$ - and $\beta$ - caseins as a result of the greater proportion of young goat cheese, which has higher intact casein content. Consequently, increasing the proportion of goat cheese having intact casein in the formulation can increase the complex modulus of the spreadable processed goat cheese. Formulation 2 and the commercial processed cow cheese showed similar acceptance by consumers, validating texture results.

\section{References}

Bennett, R. J., Trivedi, D., Hemar, Y., Reid, D. C. W., Illingworth, D., \& Lee, S. K. (2006). The effect of starch addition on the rheological and microstructural properties of model processed cheese. Australian Journal of Dairy Technology, 61(2), 157-159. 7th Dairy Science World Series Conference (DSWS), Sydney, AUSTRALIA, JUL 2425, 2006.

Brickley, C. A., Auty, M. A. E., Piraino, P., \& McSweeney, P. L. H. (2007). The effect of natural cheddar cheese ripening on the functional and textural properties of the processed cheese manufactured therefrom. Journal of Food Science, 72(9), C483C490. doi:10.1111/j.1750-3841.2007.00539. $\mathrm{x}$

Bruzzone, F., Ares, G., \& Giménez, A. (2012). Consumers' texture perception of milk desserts. II - Comparison with trained assessors' data. Journal of Texture Studies, 43(3), 214-226.

Bunka, F., Doudova, L., Weiserova, E., Cernikova, M., Kuchar, D., Slavikova, S., ... Michalek, J. (2014). The effect of concentration and composition of ternary emulsifying salts on the textural properties of processed cheese spreads. LWT-Food Science and Technology, 58(1), 247-255. doi:10.1016/j.lwt.2014.02.040

Burgos, L. (2016). Proteolysis, texture and microstructure of goat cheese. International Journal of Engineering and Applied Sciences 2394-3661, 3, 14.

Cernikova, M., Bunka, F., Pavlinek, V., Brezina, P., Hrabe, J., \& Valasek, P. (2008). Effect of carrageenan type on viscoelastic properties of processed cheese. Food Hydrocolloids, 22(6), 1054-1061. doi:10.1016/j. foodhyd.2007.05.020

Cunha, C. R., Grimaldi, R., Alcantara, M. R., \& Viotto, W. H. (2013). Effect of the type of fat on rheology, functional properties and sensory acceptance of spreadable cheese analogue. International Journal of Dairy Technology, 66(1), 54-62. doi:10.1111/j. 1471-0307.2012.00876.x

da Silva, D. F., de Souza Ferreira, S. B., Bruschi, M. L., Britten, M., \& Matumoto-Pintro, P. T. (2016). Effect of commercial konjac glucomannan and konjac flours on textural, rheological and microstructural properties of low fat processed cheese. Food Hydrocol- 
loids, 60, 308-316. doi:10.1016/j.foodhyd. 2016.03.034

Dimitreli, G., \& Thomareis, A. S. (2008). Effect of chemical composition on the linear viscoelastic properties of spreadable-type processed cheese. Journal of Food Engineering, 84(3), 368-374. doi:10.1016/j.jfoodeng . 2007.05.030

Galván, R. L. (2007). Evaluación sensorial: Quesos de cabra y oveja. Cuaderno tecnológico №5 Lácteos. Instituto Nacional de Tecnología Industrial INTI-LÁCTEOS. Retrieved from https:// www.inti.gov.ar / lacteos/pdf/cuadernotecnologico5.pdf

Guinee, T. P., \& O'Callaghan, D. J. (2013). Effect of increasing the protein-to-fat ratio and reducing fat content on the chemical and physical properties of processed cheese product. Journal of Dairy Science, 96(11), 6830-6839. doi:10.3168/jds.2013-6685

Guinee, T. (2016). Protein in cheese and cheese products: Structure-function relationships. (pp. 347-415). doi:10.1007/978-1-49392800-2_14

Guinee, T., Carić, M., \& Kalab, M. (2004). Pasteurized processed cheese and substitute/imitation cheese products. Cheese: Chemistry, Physics and Microbiology, 2, 349-394. doi:10 . 1016 / S1874 - 558X(04 ) 80052-6

Gunasekaran, S., \& Ak, M. M. (2000). Dynamic oscillatory shear testing of foods - selected applications. Trends in Food Science 83 Technology, 11(3), 115-127. doi:10.1016/ S0924-2244(00)00058-3

Hanaei, F., Cuvelier, G., \& Sieffermann, J. M. (2015). Consumer texture descriptions of a set of processed cheese. Food Quality and Preference, 40(B), 316-325. 10th Pangborn Sensory Science Symposium, Rio de Janeiro, BRAZIL, AUG 11-15, 2013. doi:10.1016/j.foodqual.2014.05.018

Hladka, K., Randulova, Z., Tremlova, B., Ponizil, P., Mancik, P., Cernikova, M., \& Bunka, F. (2014). The effect of cheese maturity on selected properties of processed cheese without traditional emulsifying agents. LWTFood Science and Technology, 55(2), 650656. doi:10.1016/j.lwt.2013.10.023
Hosseini-Parvar, S. H., Matia-Merino, L., \& Golding, M. (2015). Effect of basil seed gum (BSG) on textural, rheological and microstructural properties of model processed cheese. Food Hydrocolloids, 43, 557567. doi:10.1016/j.foodhyd.2014.07.015

Joshi, N. S., Jhala, R. P., Muthukumarappan, K., Acharya, M. R., \& Mistry, V. V. (2004). Textural and rheological properties of processed cheese. International Journal of Food Properties, 7(3), 519-530. doi:10. 1081/JFP-120040206

Kapoor, R., Metzger, L. E., Biswas, A. C., \& Muthukummarappan, K. (2007). Effect of natural cheese characteristics on process cheese properties. Journal of Dairy Science, 90(4), 1625-1634. doi:10.3168/jds. 2006-746

Kapoor, R., \& Metzger, L. E. (2008). Process cheese: Scientific and technological aspects - a review. Comprehensive Reviews in Food Science and Food Safety, 7(2), 194-214.

Le, S., Josse, J., \& Husson, F. (2008). Factominer: An $\mathrm{r}$ package for multivariate analysis. Journal of Statistical Software, 25(1), 1-18.

Lemes, A. C., Pavon, Y., Lazzaroni, S., Rozycki, S., Brandelli, A., \& Kalil, S. J. (2016). A new milk-clotting enzyme produced by bacillus sp p45 applied in cream cheese development. LWT-Food Science and Technology, 66, 217-224. doi:10.1016/j. lwt. 2015.10.038

Macku, I., Bunka, F., Voldanova, B., \& Pavlinek, V. (2009). Effect of addition of selected solid cosolutes on viscoelastic properties of model processed cheese containing pectin. Food Hydrocolloids, 23(8), 20782084. doi:10.1016/j.foodhyd.2009.03.020

Piska, I., \& Stetina, J. (2004). Influence of cheese ripening and rate of cooling of the processed cheese mixture on rheological properties of processed cheese. Journal of Food Engineering, 61(4), 551-555. 15th International Congress of Chemical Process Engineering (CHISA 2002), PRAGUE, CZECH REPUBLIC, AUG 25-29, 2002. doi:10 . 1016/S0260-8774(03)00217-6

Purna, S. K. G., Pollard, A., \& Metzger, L. E. (2006). Effect of formulation and manufac- 
turing parameters on process cheese food functionality - i. trisodium citrate. Journal of Dairy Science, 89(7), 2386-2396. doi:10. 3168/jds.S0022-0302(06)72311-6

Raynal-Ljutovac, K., Lagriffoul, G., Paccard, P., Guillet, I., \& Chilliard, Y. (2008). Composition of goat and sheep milk products: An update. Small Ruminant Research, 79(1, SI), 57-72. 5th IDF Symposium on the Challenge to Sheep and Goats Milk Sectors, Alghero, ITALY, APR 18-20, 2007. doi:10.1016/j.smallrumres.2008.07.009

Salek, R. N., Cernikova, M., Maderova, S., Lapcik, L., \& Bunka, F. (2016). The effect of different composition of ternary mixtures of emulsifying salts on the consistency of processed cheese spreads manufactured from swiss-type cheese with different degrees of maturity. Journal of Dairy Science, 99(5), 3274-3287. doi:10.3168/jds.201510028

Solowiej, B., Cheung, I. W. Y., \& Li-Chan, E. C. Y. (2014). Texture, rheology and meltability of processed cheese analogues prepared using rennet or acid casein with or without added whey proteins. International Dairy Journal, 37(2), 87-94. doi:10. 1016/j.idairyj.2014.03.003

Varela, P., \& Ares, G. (2012). Sensory profiling, the blurred line between sensory and consumer science. a review of novel methods for product characterization. Food Research International, 48(2), 893-908. doi:10.1016/j.foodres.2012.06.037

Veloso, A. C. A., Teixeira, N., \& Ferreira, I. M. P. L. V. O. (2002). Separation and quantification of the major casein fractions by reverse-phase high-performance liquid chromatography and urea-polyacrylamide gel electrophoresis - detection of milk adulterations. Journal of Chromatography A, 967(2), 209-218. doi:10 . 1016/S0021 9673(02)00787-2

Weiserova, E., Doudova, L., Galiova, L., Zak, L., Michalek, J., Janis, R., \& Bunka, F. (2011). The effect of combinations of sodium phosphates in binary mixtures on selected texture parameters of processed cheese spreads. International Dairy Jour- nal, 21 (12), 979-986. doi:10.1016/j.idairyj. 2011.06.006 